\title{
Service Learning Approach to Recycling
}

\author{
T. Jaba Priya \\ Department of Chemistry \\ Madras Christian College \\ Chennai, India
}

\author{
R. Wilfred Sugumar* \\ Head, Department of Chemistry \\ Madras Christian College \\ Chennai, India \\ wilfmcc@rediffmail.com
}

* Corresponding author

\begin{abstract}
Integrating curriculum-based service learning program into chemistry courses yields many benefits for the students such as improved cognition and practical skills. Additionally the community partner benefits from both the expertise and the services of the class. This paper describes the success story of one such program conducted by students at Madras Christian College. It involves the interaction with informal recyclers and the chemical recycling of polyethylene terephthalate (PET) waste. The stakeholders of the project were the students, informal recyclers, residential population, and an NGO. The marginalized informal recyclers were brought into mainstream society through formal solid waste collection system. This approach views the recyclers as catalysts to tackle climate change instead of viewing them as a social burden. The public was taught waste segregation and collection methods. On the whole the program resulted in improving the immediate environment and saving a wetland where dumping of waste was carried out.
\end{abstract}

Index Terms: Informal recyclers; chemical recycling; service-learning; waste management.

\section{INTRODUCTION}

Pallikaranai wetland is a fresh water swamp adjacent to the Bay of Bengal situated about $20 \mathrm{~km}$ south of Chennai city with a geographical area of $80 \mathrm{~km}^{2}$ (Figure 1). The swamp is helpful in charging the aquifers of the region with coordinates at $13^{\circ} 8^{\prime} 26.16^{\prime \prime} \mathrm{N} 79^{\circ} 54^{\prime} 21.6^{\prime \prime} \mathrm{E}$. This serves two important functions - flood control in the hinterland areas, as well as groundwater recharge. The inflow of storm water during the northeast monsoon over hundreds of years has made the marsh a unique mix of freshwater (in the north) and brackish-estuarine water in the south. ${ }^{1}$

The populace of the city of Chennai generates about 3500 tons of garbage every day. This garbage, also known as "municipal waste", is comprised of organic waste, plastic, packaging waste, paper, metal, glass, construction debris and other components like ash, sand and grit. Every day the Chennai Municipal Corporation and private collectors collect and then dump the garbage collected from the city. Dark pools of foul smelling streams are common in the area around the garbage dump in many parts of wetland in Pallikaranai ${ }^{2}$. Mass kills of frogs, fish and sometimes water birds has also been reported in the area. 


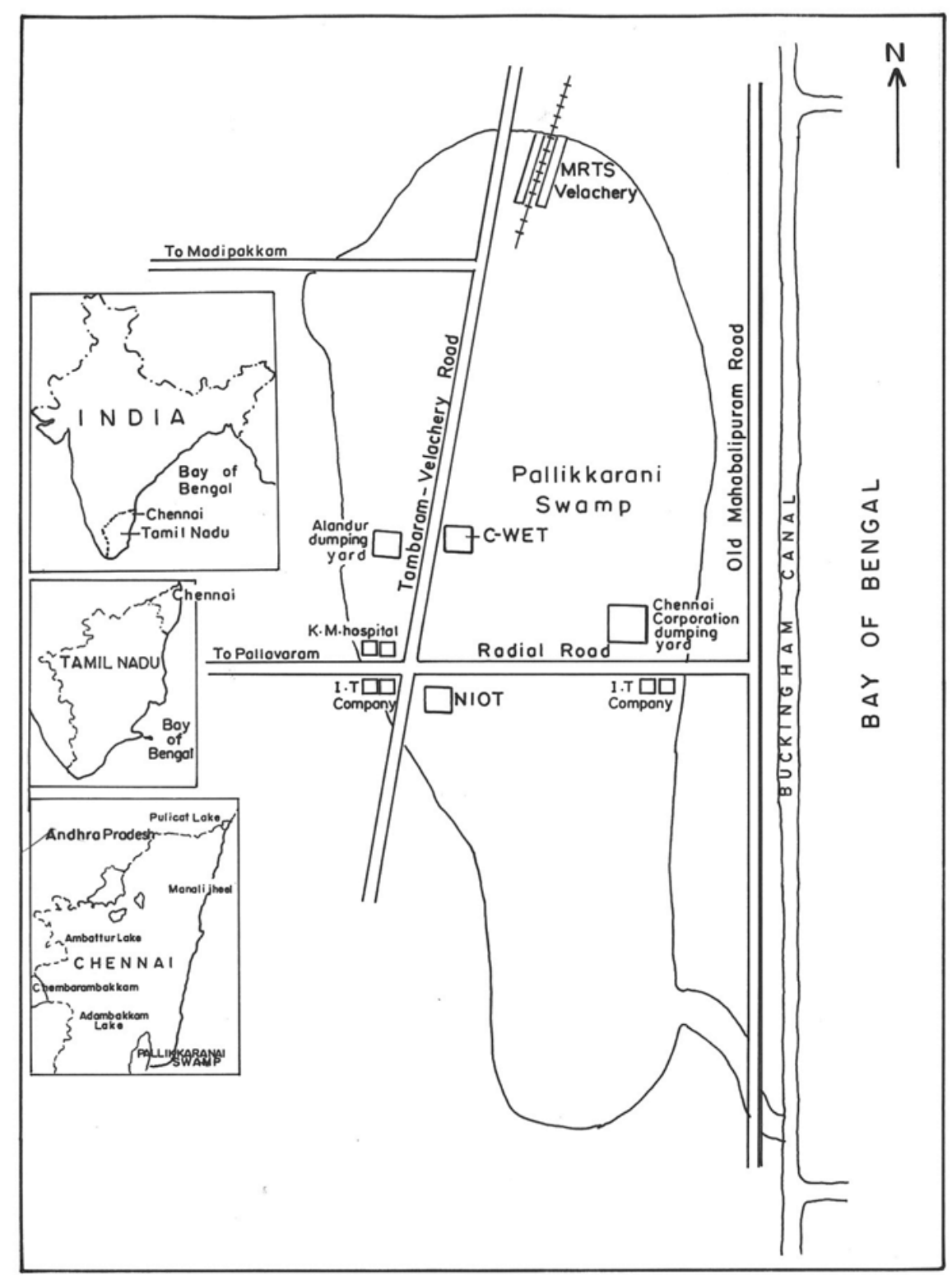

FIGURE 1

PALLIKARANAI MARSHLAND

Most of the garbage is set ablaze after being dumped. Dozens of people, including children, rummage through the smoldering garbage mounds to collect items and material that can be reprocessed or re-sold. The smoke from burning garbage poses a serious health threat to both the people working in the dumping ground and residents of the area.

As a part of curriculum, Green Chemistry ${ }^{3}$ is taught both at the undergraduate and post graduate levels in the Department of Chemistry. Apart from the theoretical explanations of the principles of Reuse, Reduce and Recycle, students carry out experiments based on these principles. One such experiment is the chemical recycling of polyethylene terephthalate (PET) bottles $^{4}$. The cleaned post consumer PET bottles are cut into flakes and pellets and chemically depolymerized in the laboratory ${ }^{5}$. The depolymerized product can be used as a raw material for the preparation of polyester fibers. 


\section{PET Waste: A New Environmental Problem}

Indiscriminate disposal of PET bottles used in the packaging of soft drinks and drinking water is an emerging environmental problem in Chennai and its adjoining areas. Statistics reveal that in Chennai, the total amount of PET bottles generated is about 140 tons per month. No proper unit for the recycling of PET bottles existed in the whole Chennai for long. The process of recycling followed an unscientific method, resulting in unauthorized bottling by unscrupulous people. Only recently, Futura Polyester Ltd, a company located in Chennai, begain to utilize the waste PET bottles in their fiber manufacturing units as raw material. The PET is depolymerized and the depolymerized product terephthalate is blended with the other raw material for making fibers.

Increasing poverty has attracted more and more people who engage in informal selective waste collection and separation. These recyclers work under unhygienic conditions to pick up the recyclable material from waste dumped at this site. They remain marginalized by the society, do not have voting rights, and are ineligible to receive social welfare schemes of the Government. Hence there arises a need to integrate them into the mainstream. This process of integration is termed as "Recovering citizenship".

These challenges led the students of Department of Chemistry to carry out Service Learning Program ${ }^{6-8}$ with the following aims:

i. to ensure that the waste PET bottles are recycled and used for the manufacture polyester fiber thereby reducing the secondary carbon footprint,

ii. to formalize the recycling process ensuring health protection to recyclers,

iii. to recover the citizenship for the recyclers so that they become eligible to get social welfare schemes of the government.

\section{METHODOLOGY}

The one-year Service Learning program involved the following stages:

A group of 25 post graduate chemistry students were the participants. The students learned in the laboratory the basis of recycling and conservation of the natural resources, along with the process of converting waste PET bottles into polyester fibers through depolymerization of PET bottles using phase transfer catalysts. They were also taken to the factory which carried out the conversion of post consumer PET bottles into terephthalic acid and then converting it into fiber. They were amazed at the large quantity of PET bottles used for this purpose. They found that though enough PET bottles are available locally for recycling, the firm imported most of their requirement from abroad. They understood the need to have a formal PET bottle collection system at the local level.

The students then visited the waste dumping yard where all the solid waste including the biodegradables was thrown. The wetland ecosystem at Pallikaranai, which is essential for the prevention of sea water intrusion and which is a biodiversity hotspot, is used as the dumping yard. The students understood the need for preservation of natural ecosystem.

They interacted with informal recyclers (so called rag pickers) who did the great job of recycling PET bottles. Many of the recyclers were illiterates but they could still make a distinction among various recyclable products.

The students were struck by the unhygienic work conditions of these informal recyclers. Handling and processing recyclable materials exposed the informal recyclers to unhealthy and 
sometimes dangerous conditions. Despite the visibility of informal recyclers in the streets, their working conditions are hardly recognized and they generally remain without a voice. Students were pained by the social exclusion of the recyclers and understood the need for recovering their citizenship.

The students realized that waste management is not solely about technical solutions to waste disposal but is more so about social and environmental concerns. They recognized the need to introduce co-management practices of recyclables, which will allow for the participation of organized recycling groups and the public in waste management. Hence a bottom up initiative involving neighborhood community in recycling was attempted.

The students wanted to utilize the knowledge gained in the laboratory for the benefit of the informal recyclers. Hence they obtained the used PET bottles collected by them and produced the raw material for fiber making through depolymerization process. This involved the assembly of simple all-glass equipment which are readily available in a chemistry laboratory (Figure 2). The depolymerized product was handed over to the recyclers so that it could be sold in the market. If the recyclers sold the PET bottles as such, they would be earning only one fifth of what they earned through the sale of depolymerized product.

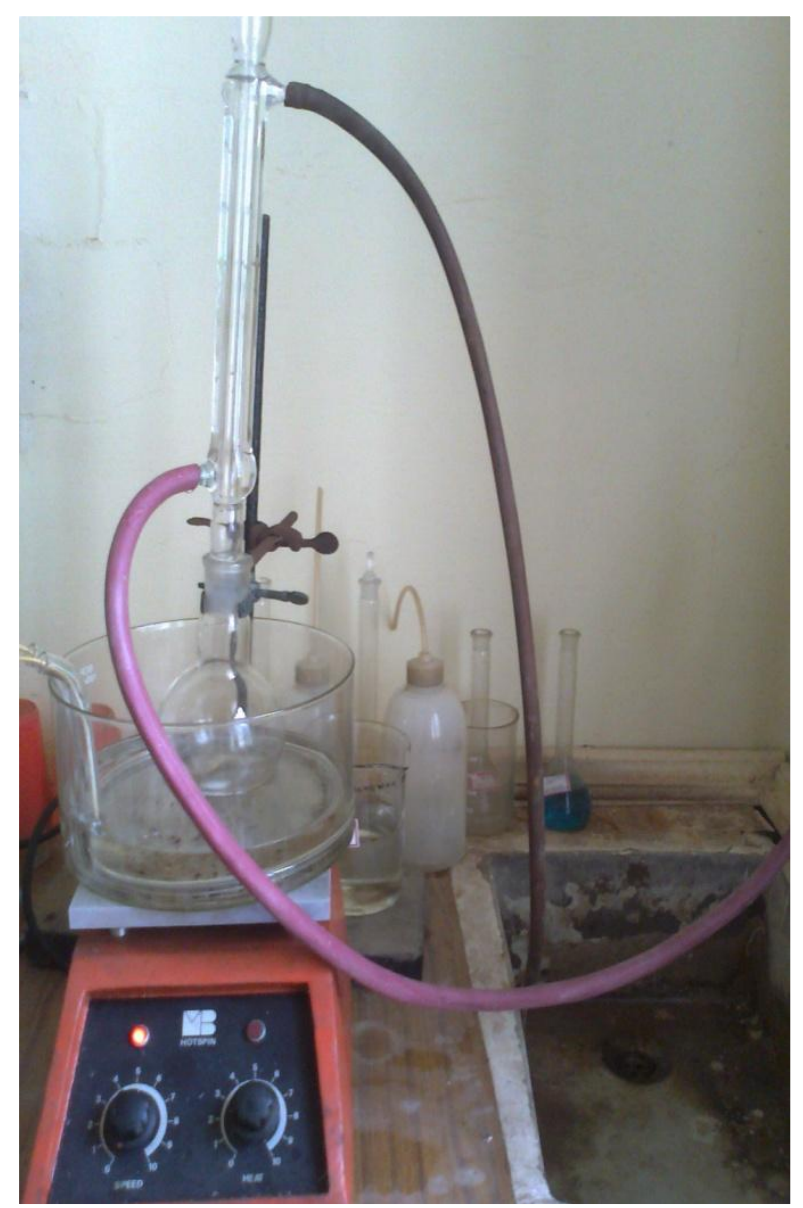

FIGURE 2

EXPERIMENTAL SETUP 


\section{OUTCOME OF THE PROJECT}

\section{Concept of Waste}

Waste is still considered as a nuisance - something the owner does not want to have or something that is abandoned. Related to this view of the waste is the widespread negative perception of those who work with waste, including informal recyclers. These people are often associated with trash and doing the dirty work, and they are stigmatized by mainstream society as a result. From a resource conservation perspective, there is no such thing as waste and dumping corresponds to wasting resources ${ }^{9,10}$. The present study would lead to a change in the prevailing view of waste. There needs to be a shift from treating our waste carelessly as useless material towards recognizing it as a resource and contributing to its recovery. This service learning program is designed to produce such a shift and in turn results in boosting the public's perception of chemistry.

\section{Carbon Footprint and Recycling}

A carbon footprint is a measure of the impact our activities have on the environment and in particular climate change. It relates to the amount of greenhouse gases produced in our day-to-day lives through our activities. The carbon footprint is a measurement of all greenhouse gases we individually produce and has units of tones (or $\mathrm{kg}$ ) of carbon dioxide equivalent.

It is also a measure of the exclusive total amount of carbon dioxide emissions that are directly and indirectly caused by an activity or is accumulated over the life stages of a product. A carbon footprint is made up of the sum of two parts, the primary footprint and the secondary footprint.

1. The primary footprint is a measure of our direct emissions of $\mathrm{CO}_{2}$ from the burning of fossil fuels including domestic energy consumption and transportation (e.g. car and plane). We have direct control of these.

2. The secondary footprint is a measure of the indirect $\mathrm{CO}_{2}$ emissions from the whole lifecycle of products we use - those associated with their manufacture and eventual breakdown. To put it very simply - the more we buy, the more emissions will be caused on our behalf.

Recycling uses less energy and produces less pollution than making things from scratch. For example:

- Making aluminum cans from old ones uses one twelfth of the energy to make them from raw materials.

- Making fibers from recycled PET takes one third the sulfur dioxide and half the nitrous oxide, than making them from scratch.

In the medium- and long term, the carbon footprint must be reduced to less than $2000 \mathrm{~kg}$ $\mathrm{CO}_{2}$ per year and per person. This is the maximum allowed level for a sustainable living.

Recycling reduces the effects of climate change in many other ways. Resource recovery diminishes and eventually eliminates the need for landfill and incinerator ${ }^{8}$. 


\section{Building Social Capital with Recycling}

A formal group of recyclers was formed and the residents in the area were advised to hand over the recyclables to these recyclers when they approach them for collection. A Non-Governmental Organization (NGO), "Hand in Hand" was partnered with in this program and they assisted in organizing the groups. They ensured effective liaison between the public and the students. Twenty two recyclers were part of this initiative. They learned about the quality and efficiency of selective collection and separation, health and risk protection financial administration and group organization. Recycling was used as a vehicle to draw public attention to the deprived living conditions in the neighborhood and it was hoped it might pave the way for the social inclusion of the informal recyclers. In the present study, most of the local residents who collaborated with the formal recycling proposal recognized the advantages of the project for their community (Figures 3 and 4).

The recyclers now collect recyclables from residents thrice a week and the waste materials come cleaner and there are more of them. Multiple stakeholder participation involves complex and often time-consuming processes. But the final results promise higher sustainability. It is a process that builds citizenship because it stresses inclusiveness and co-responsibility. It also provides important links between government and the community ${ }^{11,12}$.

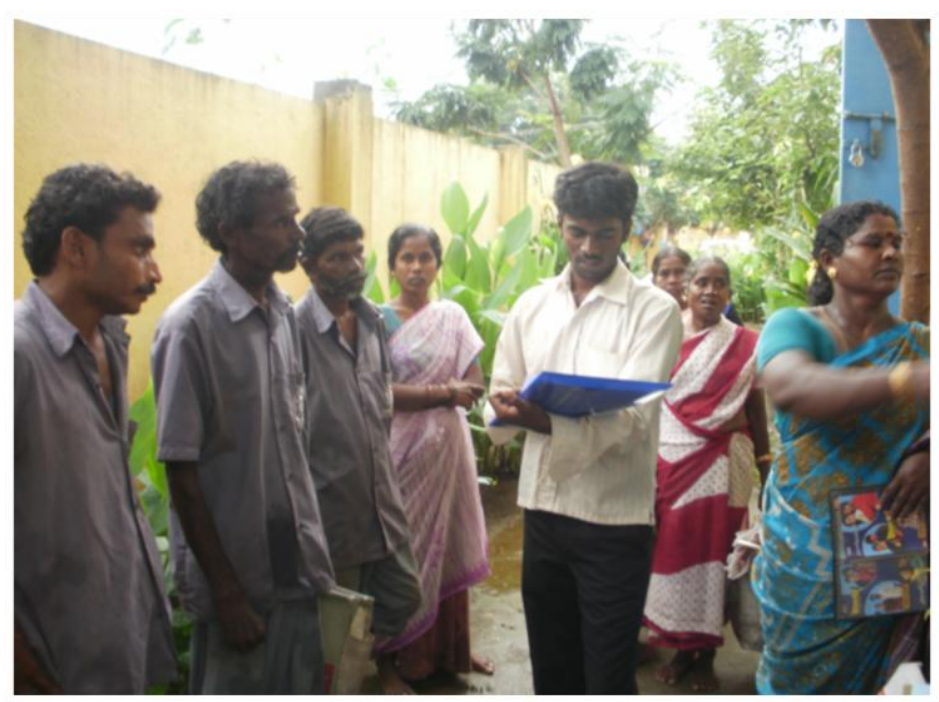

FIGURE 3

INTERACTION OF A STUDENT WITH RECYCLERS 


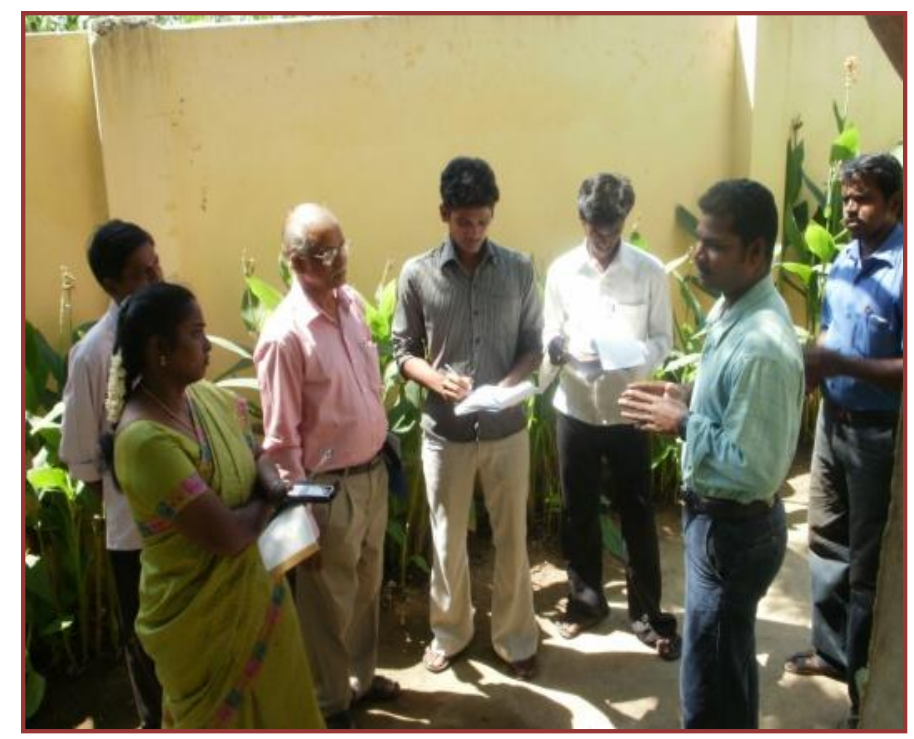

FIGURE 4

INTERACTION WITH HAND IN HAND OFFICIALS

However, such initiatives are vulnerable during their initial phases. Recyclers often suffer from lifelong exclusion. Disappointing experiences may further reiterate their preconceived ideas. These have often made the recyclers suspicious and distrustful. Consequently some of them avoided collective working schemes. A strong long-term support and strengthening of the recycling groups is necessary.

The success of the recycling programs depends on the efficient functioning of secondary materials markets ${ }^{13}$. It is important for these groups not to depend on the middleman because they pay significantly lower prices.

\section{Health Aspects}

Workers handling mixed waste, compost and recycling products face a number of health problems $^{14}$. There exists a risk of respiratory, dermal and gastrointestinal problems due to the exposure of dust, microorganisms and microbial toxins and toxic chemical substances at their workplace $^{15}$. Other occupational health risks include cuts, blunt trauma, fractures, lacerations and traffic accidents. Health concerns of informal recyclers receive little public attention and the needs and health matters of informal recyclers are hardly ever taken into consideration in waste management policies. The informal recyclers are powerless and cannot afford to seek improved and healthier working conditions. Recyclers face so many pressing problems merely trying to survive and their attention is usually concentrated on bringing home as many recyclables as possible.

Therefore the recycling activity should be formalized and the local community and government authorities should be part of this recycling program. Instead of leaving it to the individuals to collect resources, a small group may be formed and this group can interact with local community and collect the recyclables from each house.

Recyclers are environmental agents because they conduct door to door collection. They educate and communicate with the local community. Formalizing the appearance of the workers would contribute to a better relationship with the community. Formalizing the activity improves occupational health and diminishes risks. In addition, the NGO helped the recyclers to obtain voting rights and thus the citizenship of recyclers is recovered during this program. 


\section{Academic Enhancement}

The students were able to publish a technical paper ${ }^{16}$. It motivated some students to study the process thoroughly and further improvement was made in depolymerization using microwave radiation. The resulting product was very pure and the reaction time of depolymerization was reduced to a few minutes. This work was also published in an academic journal ${ }^{17}$.

\section{Threats}

There is an increasing trend towards privatization of this sector with a dominance of large-scale enterprises and multinational corporations controlling this sector ${ }^{18-21}$. These private actors prioritize incineration and landfill as waste management techniques. They have begun to play a central role in the recycling business. These developments may have serious effects on the informal recycling sector.

\section{CONCLUSIONS}

Through this service learning program the following viewpoints emerge: though recycling is not the ultimate environmental solution, it does provide an opportunity for reducing the secondary carbon footprint. It is an activity that already involves the most excluded people from the society who pick up the waste and send to recycling. Organized recycling provides the possibility of recovering citizenship of those marginalized people involved in waste recovery. Further action in this direction for sustainability of the program should focus on:

i. Inclusion: formatting inclusive waste management programs with organized recycling groups and facilitating their articulation.

ii. Equity: guaranteeing fair pay and social benefits for the service of resource recovery and assuring gender equity.

iii. Eco-health : addressing all levels of health from protecting the health of the workers to improving environmental health

iv. Eco-efficiency: reducing waste at the source, introducing co-responsibility for producers and consumers and intensifying resource recovery.

\section{ACKNOWLEDGEMENTS}

The authors thank the authorities of United Board for Christian Higher Education in Asia for the financial support to carry out this project. We also record our sincere thanks to our colleagues in the Department of Chemistry for their support and advice in implementing the project. The laboratory assistants of the Department of Chemistry certainly deserve praise for the dedication shown during the tenure of the project. 


\section{REFERENCES}

1. Pallikaranai Wetland, www.transparent chennai.com.

2.Jayashree Vencatesan, Protecting Wetland Current Science 93, No.3 , 290, 2007.

3. Anastasia P. and Warner J. C., Green Chemistry: Theory and Practice; Oxford Science Publications, Oxford, 1998.

4. Spaseska,D.and Civkaroska M .'Alkalinehydrolysisof poly (ethyleneterephthalate) recycled from the postconsumer soft-drink bottles', Journal of the University of Chemical Technology and Metallurgy, 45, 4, 379-384, 2010.

5. Raed K. Al-tamimi, Moayad N. Khalaf, May Sabri, Luma Sabri, 'Post consumer poly(ethylene terephthalate) depolymerization by waste of battery acid hydrolysis' Journal of Materials and Environmental Science 2 (2) 88-93, 2011.

6. Susan Sutheimer, "Strategies to Simplify Service-Learning Efforts in Chemistry", Journal of Chemical Education, Vol 85, No 2, 231-33. 2008.

7. Seban,Demet, "The Impact of Projects on Pre-service Teachers' Conceptualization of ServiceLearning ", Teaching and Teacher Education: An International Journal of Research and Studies, vol 32, 87-97. 2013

8. Donaghy, Kelley,J, Saxton, Kathleen, J. Service-Learning Track in Chemistry: Giving" Students a Choice", Journal of Chemical Education, vol89, No.11, 1378-1383, 2012.

9. Drackner, M, 'What is Waste? To Whom? - An anthropological Perspective on Garbage', Waste Management and Research 23, 175-81,2005.

10. Pongracz, E and Pohjola, V.' Re-defining waste, the concept of ownership and the role of waste management', Resources Conservation and Recycling 40, 141-53, 2004.

11. Baud, I., Gafakos, S Hordijk, M. and Post , J.,'Qulaity of life and Alliances in Solid Waste Management', Cities 18(1),3-12. 2001.

12. Nas, P.J.M. and Jaffe,R., 'Informal Waste Management: Shifting the Focus from Problem to Potential', Environment, Development and Sustainability, 6, 337-53, 2004.

13. Hornborg, A., 'Towards an ecological theory of unequal exchange' Ecological Economics 25,127-36, 1998.

14 .Poulsen, O.M. , Breum, N.O., Ebbehoj, N., Hansen, A.M., Ivens, U.I., van Lelieveld, D., Malmros,P., Matthiasen,L., Nielsen, B.H. and Nielsen, E.M., 'Collection of domestic waste. Review of occupational health problems and their possible causes' The Science of the Total Environment 170, 1-19, 1995.

15. Rogers, J., Englehardt,J., An.H. and Fleming, L., 'Solid waste collection service: occupational risks - survey of municipal solid waste collectors', Journal of Solid Waste Technology and Management 28(3), 154-60, 2003.

16. Jaba Priya, T., Kannadasan, K. and Wilfred Sugumar R., 'Recycling of PET waste by depolymerization using Phase Transfer Catalysts', Interntional Journl of Chemistry, $\quad 2$ (1), 86 91, 2013 .

17. Jaba Priya T., Subramee Sarkar, Shamili G. and Wilfred Sugumar, R., 'Microwave Assisted Depolymerization of Post Consumer PET Waste Using Phase Transfer Catalysts', The Chemical Educator, 19, 61-63, 2014.

18. Forsyth, T. 'Building deliberative public-private partnerships for waste management in Asia.,' Geoforum , 36, 429-39, 2005.

19. Fahmmi W.S., Urban sustainability and poverty alleviation initiatives in garbage collectors community', Cambridge: ENHR Conference 2,6 July 2004.

20. Ogu,V.I., ,'Private sector participation and municipal waste management in Benin City, Nigeria, Environment and Urbanization 12(2), 103-17, 2000.

21. Lee, Y.S.F., 'The privatization of solid waste infrastructure and services in Asia', Third World Planning Review 19(2), 139-61, 1997. 